\title{
Agricultural Integrated Living Skills Teachers' Receptivity to Assessment for Learning Practices in Malaysian Secondary Schools
}

\author{
Abdullah Mat Rashid \\ Department of Science and Technical Education \\ Faculty of Educational Studies, Universiti Putra Malaysia, Selangor \\ Malaysia \\ How Shwu Pyng \\ Department of Education, Selangor \\ Malaysia
}

\begin{abstract}
This study employed a cross-sectional survey research design to determine the receptivity to assessment for learning practices among Agricultural Integrated Living Skills (ILS) teachers in Malaysian secondary schools. The instrument used is a set of questionnaire which engaging Agricultural ILS teachers in secondary schools of Malaysia as samples. The purpose of this study specifically focused on the level of teacher receptivity and its difference towards assessment for learning practices among Agricultural ILS teachers in Malaysian secondary schools. The findings shows that the level of Agricultural ILS teachers' receptivity to assessment for learning practices were mostly at the moderate level in secondary schools. Furthermore, there are significant differences in assessment for learning practices among Agricultural ILS teachers in regards to the level of receptivity. Several recommendations are made based on the findings especially for the improvement of teacher receptivity to assessment for learning practices in schools.
\end{abstract}

Keywords: School based assessment; technical and vocational education; assessment of technical and vocational education; Agriculture teachers; theory of planned behavior

\section{Introduction}

Teacher receptivity have become the main focus in studies of large-scale educational changes under centrally controlled system which involving changes in teaching practice in the classroom (Ha, Sum, Chan, O'Sullivan, \& Pang, 2010; Lee, Yin, \& Zhang, 2011; Ma et al., 2009; Yin, Jin,\& Ma, 2008; Yin, Lee \&Jin, 2011). Furthermore, teacher receptivity found to be essential for the success of educational change because teachers are the main implementers at school level (Lee, 2010; Lee \& Yin, 2005; Shuai\& Li, 2013).Teachers will firstly assess the impact of an educational change before deciding whether receptive to the change or not (Ma, Yin, Tang, \& Liu, 2009). In this sense, educational changes found not to be implemented correctly in the classroom without teacher receptivity (Yin, Jin\& Ma, 2008). Hence a thorough understanding of the teacher receptivity is said to be able to enhance the implementation of educational change in schools (Lee et al., 2011). However teacher receptivity is a complex concept because each individual had varied attitude and response towards the change (Frahm\& Brown, 2007).

In Malaysia, previous research has demonstrated teacher receptivity as one of the crucial factors to achieve the goal of educational change in Malaysian secondary schools (Lee, 2010). However, not many researches have been conducted on teacher's receptivity, especially in the implementation of assessment for learning practices in Malaysiaas a part of educational changes. It is interestingto explore teacher receptivity from the complexity of teacher as well varieties range of schooling options as in Malaysia. At secondary education level, various options available, such as national type secondary schools, full boarding secondary schools, special secondary education, national religious secondary schools, technical secondary schools and others. The diverse range of public schooling options also give challenges to the structuring of an educational change that would receptive by all Malaysian teachers. 


\section{Teacher Receptivity to Assessment Practices}

Teacher receptivity must be understood as teachers' reaction which oriented internally towards educational changes instead of the way they behave in relation to those changes (Ma et al., 2009). In recent decades, many educational researchers have study teachers receptivity to differences large-scale educational changes under centrally controlled system in the implementation stage (Ha et al., 2010; Lee et al., 2011; Yin, Jin,\& Ma, 2008; Yin, Lee,\&Jin, 2011), including in the context of Malaysian technical and vocational education (Lee, 2010), particularly in comparison with the adoption stage (Ma et al., 2009). Agricultural in Integrated Living Skills subject is one of prevocational component that offer in secondary school. In relate to Malaysian educational changes, the implementation of Malaysian School Based Assessment (SBA) system include assessment for learning practices. However, past studies have investigated the level of teacher receptivity to the whole system of SBA and not focus on the assessment for learning practices. Therefore, Agricultural ILS teachers' receptivity to assessment for learning practices still less known according to Malaysian context.

Assessment for learning practices in Malaysian SBA system not only requiring teachers in school act as transmitter of knowledge in the teaching process and facilitator in the learning process but also completely as an assessor at schools level(LembagaPeperiksaanMalaysia, 2014a). This demand high commitment and clear direction from teachers to maximize the potential of students. Quality improvement of student learning through assessment for learning practices also demanding teachers to plan, design and conduct instruments on an ongoing basis in accordance with the student learning development guidelines in order to get information on student progress and to improve the teaching and learning practices in the classroom (LembagaPeperiksaanMalaysia, 2014b). In this context, assessment practices which focus on student's involvement and reduced teachers control towards teaching and learning activities in the classroom is not necessarily receptive by all teachers (MacPhail\&Halbert, 2010; Pedder \& James, 2012).

Teacher receptivity, including the level of acceptance among Agricultural ILS teachers, found to have association toward the implementation level of assessment practices among teachers in Malaysian secondary schools (Lee 2010; Salmiah, Ramlah, Ab Rahim, \& Abdullah, 2013; Salmiah\&Yusof, 2014). Assessment practices can be successful if the level of teacher acceptance is high (Abdul Zubir, 2007; Salmiah et al., 2013; Salmiah\&Yusof, 2014). It is, however, the issues of non-option teachers and excessive workload have resulted in the low level of teacher's acceptance to new assessment practices under SBA system among Malaysian Agricultural ILS teachers (Salmiah et al., 2013). In fact, Malaysian Agricultural ILS teachers in particular still shows the uncomfortable attitude to practice assessment correctly in the classroom even they have acquired the necessary knowledge and skills of assessment because they still hesitate to adopt SBA system as replacement of the current assessment practices (Salmiah\&Yusof, 2014). Therefore, the level of Agricultural ILS teachers' receptivity to assessment for learning practices will be examined in this study as an effort to push the implementation of assessment for learning practices among teachers in schools.

\section{Measuring of Teacher Receptivity}

Receptivity to change has been proved as a constructs which include the attitude and individual response towards the change (Frahm\& Brown, 2007). Most of the existing studies have been assessing teacher receptivity as teachers' positive attitudes and behavioral intentions towards promoting educational change according to the theory of reasoned action (Ha et al., 2010; Lee \& Yin, 2005; Ma et al., 2009). The theory of reasoned action has become fundamental in developing questionnaire and checklist for assessing teacher receptivity in various subjects through quantitative or qualitative approach (Ha et al., 2010). Definition of the receptivity level among teachers, including Agricultural ILS teachers, to changes in assessment practice in the context of Malaysia also associated with teachers' beliefs, attitudes and behavioral intentions according to the theory of reasoned action (Abdul Zubir, 2007; Salmiah et al., 2013; Salmiah\&Yusof, 2014). However linear progression from beliefs to behaviors in the theory of reasoned action only predicts rational behavior which is fully under volitional control. Therefore, it was suggested that further studies should consider other aspects in order to gain greater understanding of teacher receptivity to educational changes in schools (Ma et al., 2009).

Limitation of the theory of reasoned action has been solved and extends by Ajzen (2001) through the theory of planned behavior by adding the perceived behavioral control as a new antecedent. The theory of planned behavior emphasizes that engagement in a behavior is not only controlled by personal attitudes and social pressures but also controlled by a sense of behavioral control. 
The theory of planned behavior had a better predictive ability and proposed as an effort to address the limitations in the theory of reasoned action (Cheng, Lam,\& Hsu, 2006; Kyle et al., 2014). Nonetheless, the use of this theory in the study of teachers receptivity to educational change remains limited. Previous research began defining teacher receptivity to educational changes according to the theory of planned behavior as teachers' behavioral intentions to implement the educational change which functions as a direct determinant to the actual behavior (Lee et al., 2011; Yin, Jin,\& Ma, 2008; Yin, Lee,\&Jin, 2011).

Some of the research presented above proves that teacher receptivity which referred to the teachers' behavioral intention to implement educational changes in schools also can be predicted by the cost-benefit appraisal of the change, practicality of the change and support in schools. These three factors respectively corresponded to the three fundamental determining aspects of human behavior in the theory of planned behavior, i.e., positive evaluation of behavior, subjective norms and perceived behavioral controls (Lee et al., 2011; Yin, Jin,\& Ma, 2008). Therefore, the constructs for attitudes, subjective norms, perceived behavioral controls and behavioral intentions in the theory of planned behavior will be focused in this study in order to understand teacher receptivity with more specifically. All of the constructs in the theory of planned behavior will be adapted and used to identify the level of teacher receptivity and also its differences towards assessment for learning practices among Agricultural ILS teachers in Malaysian secondary schools.

\section{Methodology}

This study mainly aims at investigating Agricultural ILS teachers' receptivity to assessment for learning practices in their teaching throughout Malaysian secondary schools. The study was guided by the following general research questions:

i. What is the level of receptivity to Assessment for Learning practices of TVE among Agricultural ILS teachers in secondary schools?

ii. Are there significant differences in Assessment for Learning practices of TVE based on the level of receptivity among Agricultural ILS teachers in secondary schools?

This study employed a cross-sectional survey research design using a set of self-reported questionnaire which consisted of two parts. First part of the questionnaire contained 12 items which assessed on a five-point Likert scale ranging from strongly disagree (1) to strongly agree (5), where the respondents rated to what extent they are receptive to assessment for learning practices in their teaching. These items were adapted and translated to fit the Malaysian context of assessment for learning practices based on the theory of planned behavior constructs. It also contained two open-ended items to provide respondents flexibility in adding their perceptions for data enrichment. Second part of the questionnaire contained 14 items which also assessed on a five-point Likert scale ranging from very not often (1) to very often (5), where the respondents rated to what extent they made use of assessment for learning practices in their teaching. These items were adapted and translated to fit the Malaysian context accordingly based on the validated Teacher Assessment for Learning Questionnaire (TAFL-Q) developed by PatEl et al. (2013).

The instrument validation involved expert validation and pilot test to ensure the instrument construction were clear and appropriate to assess the variables in this study. The instrument was review by a group of experts and the preliminary generated items were refined according to their judgements and suggestion. Furthermore, a pilot test of the refined instrument was conducted to a small group of randomly selected respondents. Ambiguous items that had been identified were corrected for the wording clarity or removed under necessary adjustments followed by a second pilot test to ensure items were accessible to Agricultural ILS teachers in Malaysia. All of the information derived was then utilized to establish the validity while Cronbach Alpha reliability statistic was used to assess internal consistency of the instrument. The overall instrument which obtained Cronbach Alpha reliability coefficient of .856 was later used to collect data from selected respondents.

The present study used two stages cluster sampling procedure to select respondents randomly from the population of teachers who are currently teaching Agricultural ILS subject for students from Form 1 to Form 3 (age 13 to 15 years old) of secondary schools in 2017 throughout Malaysia. Selected respondents were spread across different regions in Malaysia to maximize the geographical diversity and to obtain a representative sample. Permission was requested from Ministry of Education, State Education Department and school principals to collect data from the selected teachers. Questionnaires were mailed by researcher to 428 schools along with a cover letter after prenotification and distributed by principals at each school to the selected respondents. 
Respondents were sealed their completed questionnaire in a provided envelope to assure that responses were treated confidentially and return to the researcher by mail. Appropriate follow-up procedures were carried out to encourage high response rate which including first reminder with a card to all of the respondents after mail out the original questionnaire for a week. It was then followed with a second questionnaire after another week and finally with a reminder call to the non-respondents. The responding 352 Agricultural ILS teachers throughout Malaysia representing a response rate of $82.2 \%$. Wave analysis was conducted to confirm that nonresponse error was not exists and 352 completed questionnaires were finally coded as numerical responses for data analysis.

The data obtained was analyzed with descriptive statistics (frequency, percentage and mean) and inferential statistics (One-way ANOVA) using IBM SPSS Statistic 21 software program at significant level of $p=.05$. Descriptive statistic was conducted as a first step in data analysis to determine the level of receptivity to assessment for learning practices among Agricultural ILS teachers in secondary schools. This analysis also showed which items of receptivity to assessment for learning practices to be most (and least) agree by the Agricultural ILS teachers at each school according to their perceptions. Inferential statistic as a second step in data analysis was then assessed whether differences in assessment for learning practices had occurred based on the level of receptivity among Agricultural ILS teachers throughout Malaysia.

\section{The Level of Teacher Receptivity to Assessment for Learning Practices}

The overall findings indicate that Agricultural ILS teachers perceived themselves were receptive to assessment for learning practices in their teaching at five different levels especially moderate level (Table 1).

\section{Table 1.Distribution of the respondents by five level of teacher receptivity to Assessment for Learning} practices

\begin{tabular}{lll}
\hline Level of Teacher Receptivity to Assessment for Learning Practices & Frequency & Percent \\
Very High & 18 & 5.1 \\
High & 60 & 17.0 \\
Moderate & 217 & 61.6 \\
Low & 45 & 12.8 \\
Very Low & 12 & 3.4 \\
Total & 352 & 100.0 \\
\hline
\end{tabular}

In other words, the Agricultural ILS teachers did receptive to assessment for learning in schools but the percentage of teacher receptivity at high and very high level has not reached the maximum level. This result also shows aggregate responses to each items of receptivity to assessment for learning practices which to be most (and least) agree by the Agricultural ILS teachers at each school according to their perceptions (Table 2).

Aggregate responses to each item on the questionnaire shows Agricultural ILS teachers in schools agree that they have make an effort in implementing assessment for learning practices for the Agricultural ILS subject which taught by them in schools. This high level item shows positive tendency among Agricultural ILS teachers to make effort in implementing assessment for learning practices in schools. Agricultural ILS teachers in schools also agree that they believe implementing the assessment for learning practices is valuable, beneficial and necessary. These three high level items also shows positive standpoint or psychological tendency among Agricultural ILS teachers towards assessment for learning practices in schools. 
Table 2.Distribution of mean and level by12 items of teacher receptivity to assessment for learning practices

\begin{tabular}{lll}
\hline Teacher Receptivity to Assessment for Learning Practices & Mean & Level \\
\hline Implementing assessment for learning is worth. & 62.43 & High \\
$\begin{array}{l}\text { Implementing assessment for learning is give benefit. } \\
\text { Implementing assessment for learning is important. }\end{array}$ & 62.07 & High \\
$\begin{array}{l}\text { Confident in implementing assessment for learning for the Agricultural ILS subject that I } \\
\text { teach. }\end{array}$ & 60.64 & High \\
$\begin{array}{l}\text { Have resource in implementing assessment for learning for the Agricultural ILS subject } \\
\text { that I teach. }\end{array}$ & 55.27 & Moderate \\
$\begin{array}{l}\text { Have time implementing assessment for learning for the Agricultural ILS subject. } \\
\text { Satisfy when able to implementing assessment for learning for the Agricultural ILS subject } \\
\text { that I teach. }\end{array}$ & 49.18 & Moderate \\
$\begin{array}{l}\text { Enjoy when able to implementing assessment for learning for the Agricultural ILS subject } \\
\text { that I teach. }\end{array}$ & High \\
$\begin{array}{l}\text { Worry when unable to implementing assessment for learning for the Agricultural ILS } \\
\text { subject that I teach. }\end{array}$ & High \\
$\begin{array}{l}\text { Uneasy when unable to implementing assessment for learning for the Agricultural ILS } \\
\text { subject that I teach. }\end{array}$ & 55.63 & Moderate \\
$\begin{array}{l}\text { Working hard in implementing assessment for learning for the Agricultural ILS subject } \\
\text { that I teach. }\end{array}$ & 65.98 & Moderate \\
$\begin{array}{l}\text { Willing to implementing assessment for learning for the Agricultural ILS subject that I } \\
\text { teach. }\end{array}$ & 60.64 & High \\
\hline
\end{tabular}

Agricultural ILS teachers in schools then agree that they are confident in implementing assessment for learning practices for the Agricultural ILS subject which taught by them in schools. Confidence which expressed in this high level item show that Agricultural ILS teachers trust their own ability in implementing assessment for learning practices in schools. Agricultural ILS teachers also agree that they are willing to implement assessment for learning practices for the Agricultural ILS subject. Willingness which stated in this high level item describes the positive mental state or internal reaction among Agricultural ILS teachers towards assessment for learning practices in schools. Findings of this item also in line with the extra feedback obtained via a open-ended item which revealed that the majority of Agricultural ILS teachers are willing in implementing assessment for learning practices for the Agricultural ILS subject.

Next findings shows Agricultural ILS teachers agree that they are satisfied or enjoy when they are able to implement assessment for learning practices for the Agricultural ILS subject. These two high level items show strong positive emotion which experienced by the Agricultural ILS teachers when they successfully implementing assessment for learning practices. Agricultural ILS teachers also agree that they are sad or worried when they are unable to implement assessment for learning practices for the Agricultural ILS subject. These two moderate level items show mild negative emotion which experienced by the Agricultural ILS teachers when they fail to implement assessment for learning practices. Findings for these four items can be concluded that Agricultural ILS teachers had the positive emotion at high level while controlling their negative emotion at a moderate level. The combination of such emotions will impact positively on the individual desire in performing a particular behaviour (Bagozzi, Dholakia,\&Pearo, 2007).

Individual response and reaction which oriented internally towards educational changes is said to affect a person's receptivity towards the relevant changes (Frahm\& Brown, 2007; Ma et al., 2009). Internal response and reaction towards assessment for learning practices which identified by the findings of this study includes positive personal efforts, positive standpoint or psychological tendency, confidence in self ability, willingness in implementation and also a positive combination of emotions among Agricultural ILS teachers in schools. Those related positive internal response and reaction towards assessment for learning practices among Agricultural ILS teachers is desirable to be fully supported in order to ensure their receptivity on an ongoing basis.

The result finally shows Agricultural ILS teachers in schools agree that they lack of time or resources in implementing assessment for learning practices for the Agricultural ILS subject which taught by them in schools. Findings for these two moderate level items are also supported by the time and resources constraints which stated by the Agricultural ILS teachers as one of their problems and reasons for disagreeing to practice assessment for learning in schools. Agricultural ILS teachers explained that time and resources constraints which suffered by them tend to hamper the assessment implementation especially in form of practical until the existence of disagree feelings to implement assessment for learning practices for the Agricultural ILS subject which taught by them in schools. 


\section{Differences in Assessment for Learning Practices of TVE}

Differences in assessment for learning practices of TVE had further assessed based on the level of receptivity among Agricultural ILS teachers throughout Malaysian secondary schools. Discussion in the earlier part has point out distribution of Agricultural ILS teachers by different level of their receptivity to assessment for learning practices. In addition, results in present study convinced that there was a significant difference in assessment for learning practices among Agricultural ILS teachers with respect to their receptivity level (Table 3).

Table 3.One-way ANOVA for the teacher receptivity to assessment for learning practices

\begin{tabular}{lllllll}
\hline \hline Variable & $S S$ & $d f$ & $M S$ & $F$ & $p$ & $\eta^{2}$ \\
\hline Teacher Receptivity & & & & 31.522 & $.001 *$ & .267 \\
Between Groups & 9354.847 & 4 & 2338.712 & & & \\
Within Groups & 25745.153 & 347 & 74.194 & & & \\
Total & 35100.000 & 351 & & & & \\
\hline
\end{tabular}

Note: $* p<.05$.

The comparison result subsequently showed that assessment for learning practices is more frequent among Agricultural ILS teachers who indicating their receptivity at the level of low to very high compared the level of very low. The next significant findings also shows that assessment for learning practices is more frequent among Agricultural ILS teachers who indicating their receptivity at the level of very high or high compared with the level of moderate or low. However, results of this study also indicates that there were no significantly difference in assessment for learning practices between Agricultural ILS teachers who indicating their receptivity at the level of very high or high. Agricultural ILS teachers who indicate their receptivity at the level of moderate or low also in turn found to be practicing assessment for learning in schools with the same frequency.

\section{Conclusions and discussion}

Present study was highlighted worries about the unsatisfactory level of teacher receptivity to assessment for learning practices among Agricultural ILS teachers in Malaysian secondary education system. A finding of this study shows Agricultural ILS teachers are receptive to assessment for learning practices in schools but it has yet reached the maximum level of receptivity. Such findings also found in accordance with the extra feedback from Agricultural ILS teachers which obtained via two related open-ended items. Around three-fifths of the total of Agricultural ILS teachers involved in this study admitted to agree or willing while other teachers disagreed or not willing to implement assessment for learning practices for the Agricultural ILS subject which taught by them in schools.

Previous study shows that the level of teacher receptivity, including the level of teacher acceptance, also showed significant relationship on assessment practices among teachers in Malaysian secondary schools. For example,finding from several studies shows that the practice of Competency Assessment Modular Certification (CAMC) among vocational teachers and School Based Assessment (SBA) among Agricultural ILS teachers (Lee, 2010; Salmiah et al., 2013; Salmiah\&Yusof, 2014). Moreover, present study found that assessment for learning practices was significantly dependent on the level of teacher receptivity among Agricultural ILS teachers. This finding further explains the importance of teacher receptivity level to assessment for learning practices among Agricultural ILS teachers in schools.

In conclusion, findings of this study reveals that majority of the Agricultural ILS teachers were receptive to assessment for learning practices at a moderate level. Some of them face constraint with time or resources that lead to lessen their level of receptivity. The findings also shows that the enhancement of assessment for learning practices in school is assured among Agricultural ILS teachers in schools at least from the low level to very high. This study provide a better understanding of the current phenomenon and thus several recommendations are made based on the results especially to improve the level of teacher receptivity on assessment for learning practices among Agricultural ILS teachers in schools. It is recommended the education authority needs to review the school based assessment system to identify the shortcomings such as time and resources in the existing assessment system. This is true in order to increase the level of teacher receptivity to assessment for learning practices. A sufficient range of formal briefing or seminars on the importance and effectiveness of assessment for learning practices also recommended to be well-designed and given to the in-service teachers on a periodic basic. 
All design formal briefing or seminars might be conduct at various levels including the federal, state, district or school levels with the aim to ease negative feelings towards the implementation of assessment for learning among Agricultural ILS teachers in schools. School administrators as the closest authority to the Agricultural ILS teachers in turn should give personal support to those who successfully implemented the assessment for learning. For example identify the teachers and given praise to them in a school meeting. School administrators also can give recognition to individual teachers who implement the assessment for learning with excellent performance, e.g. nominate them as excellent service award recipients. Such efforts are expected to develop motivation at all teachers while increasing the level of teacher receptivity to assessment for learning practices continuously at school level.

\section{Funding}

The author(s) received no financial support for the research, authorship, and/or publication of this article.

\section{References}

Abdul Zubir Haji Abdul Ghani.(2007). PelaksanaanPenaksiranBerasaskanSekolah di Kalangan Guru TingkatanTiga.(Unpublished $\mathrm{PhD}$ thesis).Universiti Malaya (UM), Kuala Lumpur, Malaysia.

Bagozzi, R. P.; Dholakia, U. M., \&Pearo, L. R. K. (2007).Antecedents and consequences of online social interactions. Media Psychology, 9/1, 77-114.

Chan, Y. F., \&Gurnam, K. S. (2012).School-based assessment among ESL teachers in Malaysian secondary schools. Journal of the Malaysian Education Deans' Council, 9, 75-87.

Cheng, S., Lam, T., \& Hsu, C.H.C. (2006). Negative word-of-mouth communication intention: An application of the TPB. Journal of Hospitality \& Tourism Research, 30/1, 95-116.

Frahm, J. A., \& Brown, K. A. (2007). First steps: Linking change communication to change receptivity. Journal of Organizational Change Management, 20/3, 370-387.

Ha, S. C. A.; Sum, K. W. R.; Chan, W. K. D.; O’Sullivan, M., \& Pang, O. H. B. (2010). Effects of a professional development programme on teacher receptivity and curriculum change in Hong Kong Physical education. Educational Research Journal, 25/1, 47-80.

Huang, K. C.; Chen, S. C., \&Farn, C. K. (2014). The effect of anonymity on virtual communities usage - Facebook versus BBS. International Journal of Innovation in Management, 2/1, 1-20.

Kyle, V.A., White, K.M., Hyde, M.K., \&Occhipinti, S. (2014). The role of goal importance in predicting university students' high academic performance. Australian Journal of Educational \& Developmental Psychology, 14, 17-28.

Lee, C. K. J.; Yin, H. B.; Zhang, Z. H., \&Jin Y. L. (2011).Teacher Empowerment and Receptivity in Curriculum Reform in China. Chinese Education and Society, 44/4, 66-83.

Lee, L. H. (2010). Structural Equation Modeling of Factors Influencing The Implementation of Competency Assessment and Modular Certification (CAMC) in Malaysia Secondary Schools. (Unpublished PhD thesis).Universiti Malaya (UM), Kuala Lumpur, Malaysia.

LembagaPeperiksaan Malaysia.(2014a). Panduan Pengurusan Penaksiran Berasaskan Sekolah. Kuala Lumpur: KementerianPendidikan Malaysia (KPM).

LembagaPeperiksaan Malaysia.(2014b). Soalan-soalan Lazim Penaksiran Berasaskan Sekolah. Kuala Lumpur: KementerianPendidikan Malaysia (KPM).

Ma, Y. P.; Yin, H. B.; Tang, L. F., \& Liu, L. Y. (2009). Teacher receptivity to system-wide curriculum reform in the initiation stage: A Chinese perspective. Asia Pacific Education Review, 10/3, 423-432.

Pat-El, R. J.; Tillema, H.; Segers, M., \&Vedder, P. (2013). Validation of Assessment for Learning questionnaires for teachers and students. British Journal of Educational Psychology, 83/1, 98-113.

SalmiahJaba; RamlahHamzah; Ab. Rahim Bakar, \& Abdullah Mat Rashid. (2013). Acceptance towards School Based Assessment among Agricultural Integrated Living Skills teachers: Challenges in implementing a holistic assessment. Journal of Technical Education and Training (JTET), 5/1, 44-51.

SalmiahJaba,\&Yusof Ibrahim. (2014). Teachers' readiness and acceptance in School Based Assessment practices: Validation model using Structural Equation Modeling. Scottish Journal of Arts, Social Sciences and Scientific Studies, 19/5, 137-150.

Shuai, F., \& Li, C. (2013).High School Task-based Language Teaching in Mainland China. In E.H. Law \& C. Li (Eds), Curriculum Innovations in Changing Societies: Chinese Perspectives from Hong Kong, Taiwan and Mainland China (pp. 229-252). Rotterdam, The Netherlands: Sence Publishers.

Yin, H. B.; Jin, Y. L., \& Ma, Y. P. (2008).The structural equation model of teacher receptivity. Educational Research and Experiment, 1/3, 62-66.

Yin, H. B.; Lee, C. K. J., \&Jin, Y. L. (2011). Teacher Receptivity to Curriculum Reform and the Need for Trust: An Exploratory Study from Southwest China. The Asia-Pacific Educational Researcher, 20/1, 35-47. 